\title{
Extranjerización e internacionalización de las burguesías latinoamericanas: el caso argentino
}

\author{
Martín Schorr* y Andrés Wainer**
}

\section{Resumen}

El presente trabajo analiza el proceso de extranjerización de la economía argentina sucedido a partir de 1990, dentro de la denominada posconvertibilidad (2002 en adelante). Tomando como referencia las tendencias a la internacionalización productiva prevalecientes a nivel mundial y regional, se indaga principalmente sobre las formas en las que ha sido asumido este proceso en las fracciones predominantes del capital local.

\begin{abstract}
This paper analyzes the process of delocalisation of the Argentinian economy since 1990, within the so called posconvertilidad (2002 onwards). It primarily explores the ways in which this process has been assumed in the dominant fractions of local capital, taking as a reference the global and regional prevalent trends to productive internationalization.
\end{abstract}

Palabras clave: nacionalismo, Revolución Cubana, Unión Soviética, comunismo, democracia, Nueva Izquierda, Guerra Fría, intelectual público.

Keywords: nationalism, Cuban Revolution, Soviet Union, communism, New Left, Cold War, public intellectual.

* Doctor en Ciencias Sociales. Investigador del área de Economía y Tecnología de la Facultad Latinoamericana de Ciencias Sociales, sede Argentina y del CONICET y docente en la Facultad de Ciencias Sociales de la Universidad de Buenos Aires, en el Instituto de Altos Estudios de la Universidad de San Martín y en la maestría en Economía Política de la FLACSO.

** Doctor en Ciencias Sociales. Investigador del área de Economía y Tecnología de la Facultad Latinoamericana de Ciencias Sociales, sede Argentina y del CONICET y docente en la Facultad de Ciencias Sociales de la Universidad de Buenos Aires y en el Instituto de Altos Estudios de la Universidad de San Martín.

Se agradecen los comentarios realizados por los evaluadores anónimos. Desde ya, los errores u omisiones que pudieran existir son exclusiva responsabilidad de los autores. 


\section{Introducción}

a globalización financiera y productiva se ha caracterizado, entre otras cuestiones, por una fuerte expansión de los flujos financieros y comerciales, así como por la internacionalización de los procesos productivos, lo cual ha permitido el crecimiento acelerado de grandes corporaciones transnacionales. América Latina no ha sido la excepción, por el contrario, exhibe un sustancial incremento de la presencia del capital extranjero en su territorio, en tanto que algunas empresas locales se expandieron hacia el exterior. Ciertamente, la presencia de grandes empresas transnacionales en los países latinoamericanos no es una novedad circunscripta al período más reciente, dado que las mismas han estado presentes desde hace más de un siglo. No obstante, el carácter y el peso de las mismas, así como su rol, han variado significativamente en las últimas décadas.

En una primera etapa previa a la sustitución de importaciones, la llegada del capital extranjero a la región latinoamericana estuvo motivada fundamentalmente por la necesidad de abastecer la creciente demanda de materias primas y alimentos de los países centrales, dado que en los países productores de este tipo de bienes se llevaba a cabo un empleo más extensivo e intensivo de la fuerza de trabajo. Esto derivó en una menor composición orgánica del capital que en los países centrales así como en la posibilidad de obtener un mayor plusvalor y, con ello, una tasa de ganancia más alta que en el centro. Sin embargo, la propia exportación de capital hacia la periferia supuso un aumento de la productividad y una elevación de la composición orgánica, lo cual determinó una reducción en el valor de las mercancías y una caída en la tasa de ganancia. Dicha caída determinó la reversión de los hasta entonces favorables términos de intercambio (Marini, 2007).

En el caso particular de Argentina, el ingreso del capital extranjero estuvo matizado por la alta productividad de la actividad agropecuaria y el fuerte peso de la oligarquía terrateniente. En este sentido, la percepción de una renta diferencial a raíz de la producción agropecuaria le permitió a Argentina consolidar una poderosa clase dominante local que se asoció sin mayores conflictos al capital extranjero al proveerle éste de los medios necesarios para poder comercializar la producción agropecuaria (ferrocarriles, infraestructura, etc.). Este capital también proveía los bienes suntuosos que consumía la productividad a partir de los ingresos provenientes de las exportaciones. 
Las dos guerras mundiales y el inicio de distintos procesos sustitutivos de importaciones permitieron el desarrollo de burguesías locales en América Latina, especialmente en Brasil y Argentina. No obstante, a mediados de siglo XX, las empresas extranjeras con base industrial se fueron insertando en los sectores más dinámicos de las economías latinoamericanas, convirtiéndose en la mayoría de los casos, en la nueva fracción hegemónica dentro del bloque dominante. Por entonces, se sostenía que las necesidades de desarrollo de la industria local excedían las capacidades de ahorro interno. Se suponía que el ingreso de grandes empresas multinacionales beneficiaría a los países subdesarrollados gracias al impulso de una diversificación de la estructura industrial y la transferencia de la tecnología más avanzada. Esto eliminaría los problemas relacionados a la falta de producción local en eslabones clave para la cadena productiva, así como problemas derivados de contar con una industria "infantil", de la falta de economías de escala y la mencionada "insuficiencia" del ahorro doméstico.

Más allá de los resultados obtenidos por cada país a partir del ingreso generalizado del capital extranjero durante la segunda mitad del siglo pasado, la situación en los últimos veinte años muestra significativas diferencias con la imperante en ese entonces. Si anteriormente las filiales llevaban a cabo la producción de forma autónoma manejadas por directivos locales en la actualidad, la mayor parte de las directivas sobre el proceso de producción proceden directamente de la casa matriz. Ésta tiene en cuenta las necesidades globales de la compañía, lo cual incluye los procesos parciales de producción en las filiales restantes alrededor del planeta.

Hasta mediados de la década de 1970, la rentabilidad de las filiales de las empresas transnacionales dependía, a mediano plazo, del crecimiento del mercado interno y puesto que por lo general la capacidad instalada superaba la capacidad de absorción del mercado del grado de protección que gozaba el mismo. En cambio, a partir de la década de 1990, la rentabilidad pasó a depender de la relación entre el costo local de producción y el precio del mercado mundial. De esta manera, la inversión extranjera directa sólo se justifica si los costos son lo suficientemente reducidos y permiten la exportación o, si a pesar de tener costos más elevados, aún justifican la subsistencia de la inversión para el abastecimiento del mercado interno. Esta última situación es similar a lo que ocurría hasta mediados de la década de 1970, aunque a diferencia de aquel entonces, buena parte de los segmentos más relevantes del proceso productivo suelen ser relocalizados debido a los menores costos que se obtienen en otros sitios.

La aplicación de un conjunto de reformas asociadas al paradigma neoliberal a comienzos de la década de 1990 favoreció la expansión de 
las empresas transnacionales, ya que permitió incrementar su capacidad competitiva a partir de la posibilidad de localizar distintos fragmentos de su producción en donde los costos fueran menores. En este sentido, la transnacionalización del gran capital exige que las distintas fracciones capitalistas alcancen un tamaño adecuado para operar en dichos mercados, lo cual origina un acelerado incremento de la concentración y centralización económica y otorga al capital extranjero una ventaja competitiva decisiva sobre las fracciones "puramente" nacionales (Arceo, 2005). Para subsistir en este contexto, y frente a la desaceleración general del crecimiento del mercado, los grandes capitales locales han procurado profundizar su inserción en el mercado mundial y/o regional.

En ese marco, se puede afirmar que en América Latina se ha pasado por dos etapas. La primera, de ingreso en un modo de acumulación en el cual se procuraba atraer a las firmas extranjeras y, eventualmente, inducir el desarrollo del capital nacional a través de una política arancelaria e industrial, cuyo objetivo era reproducir la estructura de producción y consumo del centro. En la segunda etapa la región entró a otro esquema de acumulación en el cual, dentro de un marco librecambista, el crecimiento ha pasado a estar basado principalmente en las exportaciones, las cuales son determinadas por las ventajas absolutas de cada país (Arceo, 2009). Si bien a distintos tiempos y niveles estas transformaciones han significado cambios en la composición de los bloques dominantes y un reacomodamiento de las distintas clases y fracciones de clase. Al respecto, hay dos procesos que se destacan y que, con mayor o menor intensidad, se han dado en los países más grandes de la región: por un lado, una creciente extranjerización de la economía y, particularmente, de las grandes empresas; por otro, cierta "internacionalización" de empresas locales.

Argentina no ha sido la excepción a este proceso, aunque quizá se destaque sobre el resto de los países debido a la intensidad y rapidez del proceso de extranjerización vivido durante la década de 1990, teniendo en cuenta, sobre todo, que era uno de los países de la región con mayor presencia de empresas nacionales. Como contracara de este proceso de extranjerización, se observan algunos grupos económicos locales que han seguido estrategias de internacionalización con relativo éxito.

En este artículo se intenta dimensionar el proceso de extranjerización que sufrió la cúpula empresarial argentina en las últimas dos décadas e identificar los casos de internacionalización "exitosa" de los grupos económicos locales. La principal hipótesis que guía la investigación supone que la adopción de un conjunto de reformas estructurales de corte neoliberal en Argentina determinó una forma de inserción "pasiva" en la globaliza- 
ción que en lugar de ofrecer nuevas oportunidades para desarrollar una nueva y poderosa burguesía nacional, tiende a reforzar la subordinación de la misma al capital extranjero.

\section{El proceso de extranjerización de la cúpula empresarial argentina}

Las reformas estructurales aplicadas en la mayor parte de los países latinoamericanos en la década de 1990 estuvieron inspiradas en el célebre "Consenso de Washington". La apertura y desregulación de las economías y las privatizaciones de algunas de las principales empresas públicas permitieron cierta confluencia temporal de intereses entre los grandes grupos económicos locales y el capital extranjero. Si bien las grandes firmas latinoamericanas, especialmente las originarias de Brasil y México, crecieron a comienzos de la década, igualmente perdieron participación relativa a manos del capital extranjero dentro de la élite empresarial (Garrido y Peres, 1998).

En ese contexto de economías abiertas y desreguladas junto a importantes incentivos a la inversión extranjera, las grandes firmas industriales de origen local se vieron obligadas a optar por una reconversión estratégica que les permitiera competir globalmente y crecer en el exterior lo que requería de enormes recursos financieros, tecnológicos y de comercialización o venderse "bien" al capital extranjero en un momento en que las monedas de la región se encontraban sobrevaluadas. En todos los casos predominó esta segunda opción, aunque quizás Argentina haya sido el país en donde este fenómeno adquirió mayor intensidad.

En los años noventa, el conjunto de la gran burguesía argentina dio su apoyo a las reformas estructurales "pro-mercado" impulsadas por el gobierno de Menem, las cuales, junto a algunas políticas públicas que tendieron a favorecer la Inversión Extranjera Directa (IED), ${ }^{1}$ dieron como resultado un notable incremento de la participación de las empresas transnacionales en la economía argentina. En un principio, el grueso de la IED se dirigió en buena medida al sector no transable especialmente hacia las firmas de servicios públicos privatizadas, las cuales fueron las más rentables del

1 Dos ejemplos paradigmáticos son la continuidad, y posterior reafirmación con la modificación de 1993, de la Ley de Inversiones Extrajeras sancionada durante la última dictadura cívico-militar de 1976-1983 ( $\mathrm{N}^{\circ}$ 21.382) y la firma de 58 Tratados Bilaterales de Inversión (TBI) con las principales potencias económicas. A esta se suman en la década de 1990 los regímenes de privilegio en la industria automotriz y la minería, el incentivo a la participación del capital extranjero en las privatizaciones de las empresas estatales y los beneficios vinculados a la importación de bienes de capital. 
conjunto de la economía (Abeles, 1999), mientras que en la segunda mitad de la década, hubo una importante desnacionalización en el interior del sector productivo, principalmente, aunque no de forma exclusiva, en las ramas que contaban con ventajas absolutas, sobre todo aquellas vinculadas a la producción agroindustrial, minera y petrolera y de otros commodities.

Resulta por demás interesante analizar los rasgos generales que asumió este proceso de extranjerización dentro del universo de grandes compañías. Entre otras cosas, este suceso brinda la posibilidad de indagar en dos planos sumamente relevantes: a) el nivel de concentración en el conjunto de la economía nacional considerando tanto el peso de la élite empresarial, así como el valor de las diversas fracciones del capital que la conforman, y b) la

\section{Gráfica 1. Participación de las 500 empresas más grandes de Argentina en el} valor bruto de producción, en el valor agregado bruto y en las exportaciones nacionales, según el origen del capital de las firmas, 1993-2001 y 2002-2008

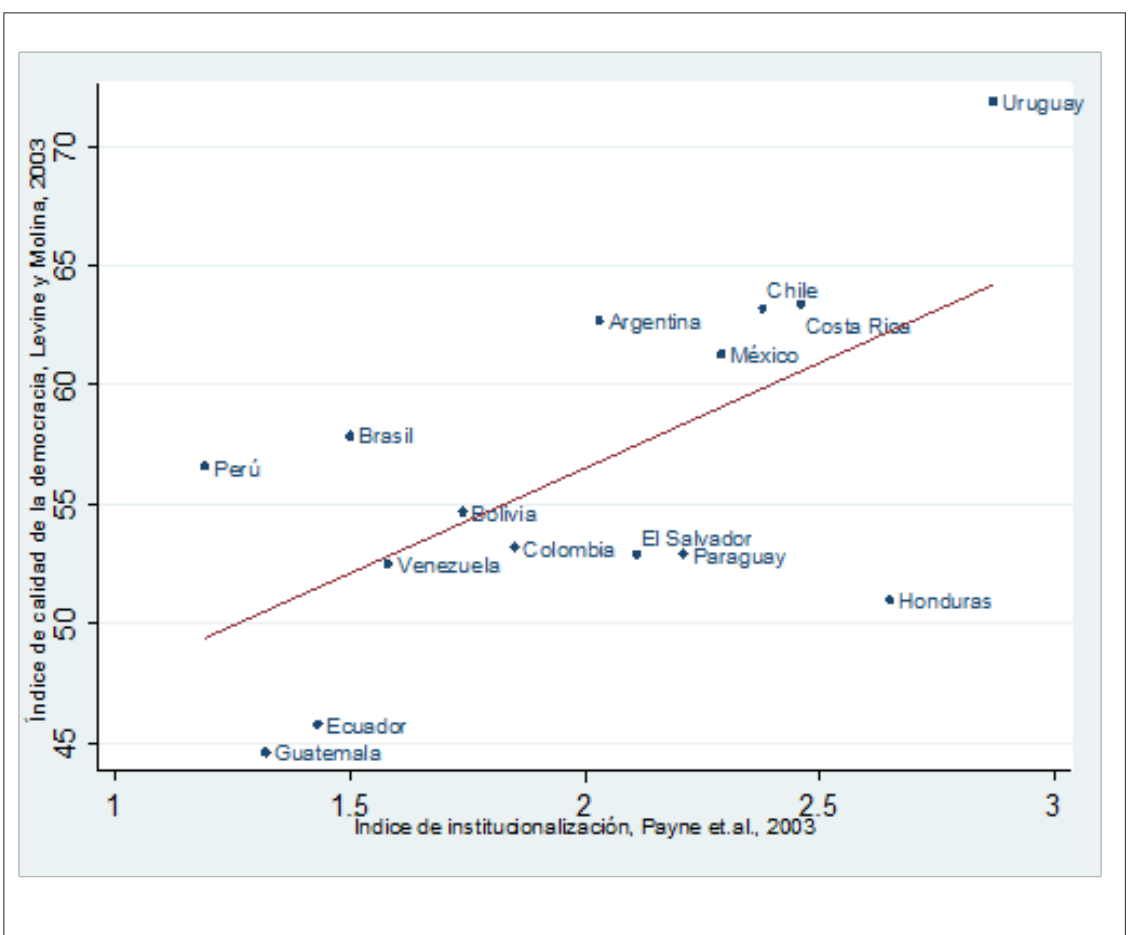

Fuente: Elaboración propia en base a tabulados especiales de la Encuesta Nacional a Grandes Empresas del INDEC. 
presencia de las compañías extranjeras que detentan el predominio económico en Argentina, a partir de su participación en las 500 firmas líderes. ${ }^{2}$

Los datos aportados por la gráfica 1 expresan el considerable aumento que experimentó el grado de concentración de las 500 firmas más grandes dentro del agregado nacional entre el régimen de convertibilidad y el que le sucedió tras la implosión del mismo en 2002; ello, cualquiera sea la variable que se tome en cuenta: valor bruto de producción, valor agregado bruto y exportaciones.

En efecto, la gravitación media de la élite empresarial en la producción pasó del 21.2 por ciento al 32.1 por ciento entre los períodos 1993-2001 y 2002-2008 (promedios anuales); mientras que en el caso del valor agregado, la presencia de las grandes firmas aumentó casi el 60 por ciento, para cristalizarse en la posconvertibilidad en el 24.2 por ciento del total del país. El tema de las ventas externas merece una mención especial por ser justamente uno de los principales elementos que se buscó favorecer a partir de la reducción de los costos absolutos a través de la devaluación de la moneda. En este aspecto, insoslayable para el abordaje del actual esquema de acumulación, las corporaciones exportadoras que integran la élite empresarial explicaron casi tres cuartas partes del total de las exportaciones del país en la posconvertibilidad (7.7 puntos porcentuales más que en el período 1993-2001). Así, no sólo se trata de un acotado número de grandes compañías que asumen un papel protagónico en la generación de riqueza sino que, en ese escenario, son los actores centrales y decisivos en cuanto a obtención de divisas, fenómeno para nada desdeñable si se atiende al rol que le ha correspondido al superávit comercial dentro de la construcción de los senderos macroeconómicos durante la posconvertibilidad. En realidad, el poder económico que se asocia al alto y creciente grado de concentración que exhiben estas compañías en el plano agregado se ve potenciado, a su vez, por su presencia determinante y creciente. Esto en cuanto a la generación de divisas, lo que reforzó su ya de por sí considerable capacidad de veto sobre la orientación de la política económica.

Las evidencias que brinda la gráfica 1 indican que la presencia de las empresas nacionales y las asociaciones en la economía nacional se redujo

2 Se trata de la información proporcionada por la Encuesta Nacional a Grandes Empresas (ENGE) que elabora el INDEC con periodicidad anual. En cuanto al origen del capital de las firmas del panel, la ENGE delimita tres categorías: aquellas controladas por capitales foráneos (que aquí se denominan empresas extranjeras); aquellas en las que la participación transnacional en el capital social es superior al 10 por ciento y menor o igual al 50 por ciento (asociaciones); y aquellas controladas por capitalistas locales (empresas nacionales, que pueden incluir hasta un 10 por ciento de participación extranjera en el "paquete" accionario). 
en todas las variables bajo análisis., mientras que las compañías extranjeras detentaron una mayor gravitación agregada, al punto de alcanzar guarismos que denotan el elevado y creciente predominio económico que experimenta este segmento del capital concentrado interno en la posconvertibilidad. En términos más específicos, la participación de las corporaciones extranjeras que componen la élite, llevaron a que, en el valor bruto de producción nacional, éste aumentara en 12.3 puntos porcentuales entre los períodos 1993-2001 y 2002-2008, incremento que fue de 10.3 puntos porcentuales a partir de considerar el valor agregado bruto. A raíz de ello, la presencia de las firmas extranjeras líderes en la posconvertibilidad alcanzó, respectivamente, el 24.2 por ciento y 19.2 por ciento de la producción y el producto bruto nacional.

En lo concerniente al comercio exterior, se verifica un comportamiento similar: la incidencia de las ventas externas de las firmas extranjeras en el total del país pasó de un promedio del 41.7 por ciento en la etapa 1993-2001 a otro del 57 por ciento en 2002-2008. De este modo, al elevado grado de concentración en las exportaciones de la cúpula empresarial con sus implicaciones en términos del poder de coacción que le otorga ser importantes generadores de divisas debe adicionarse la participación por demás elevada y creciente de un número acotado de oligopolios extranjeros en las mismas.

Con el propósito de interpretar estos resultados, resulta pertinente indagar en algunos puntos de inflexión que fueron asumidos por la movilidad interna de la élite al cabo del período estudiado. El cuadro 1 permite visualizar una primera oleada de desnacionalización del panel de las 500 grandes empresas durante el trienio 1993-1995. En esta etapa puede advertirse que las compañías foráneas pasaron de 161 a 186 firmas, lo que en términos de su participación en el valor de producción de la cúpula significó un aumento de 11.4 puntos porcentuales, al pasar de representar el 33.8 por ciento al 45.2 por ciento. Ello, en el marco de una caída en el peso relativo de las compañías nacionales y las asociaciones. 
Cuadro 1. Evolución de la cantidad de empresas y del peso relativo en el valor bruto de producción de las 500 empresas más grandes de Argentina según el origen del capital de las firmas*, 1993-2008

\begin{tabular}{|l|c|c|c|c|c|c|}
\hline \multirow{2}{*}{ Año } & \multicolumn{3}{|l|}{ Cantidad de empresas } & \multicolumn{2}{l|}{ Valor bruto de producción } \\
\cline { 2 - 7 } & Nacionales & Asociaciones & Extranjeras & Nacionales & Asociaciones & Extranjeras \\
\hline 1993 & 281 & 58 & 161 & 40.0 & 26.2 & 33.8 \\
1994 & 258 & 68 & 174 & 36.5 & 26.9 & 36.6 \\
1995 & 248 & 66 & 186 & 35.7 & 19.1 & 45.2 \\
1996 & 234 & 62 & 204 & 31.4 & 17.1 & 51.5 \\
1997 & 211 & 55 & 234 & 27.5 & 11.5 & 61.0 \\
1998 & 206 & 53 & 241 & 25.7 & 11.8 & 62.4 \\
1999 & 189 & 56 & 255 & 24.4 & 9.9 & 65.7 \\
2000 & 182 & 56 & 262 & 20.9 & 10.9 & 68.1 \\
2001 & 175 & 55 & 270 & 20.7 & 10.3 & 69.0 \\
\hline 1. Prom. convert. & 220 & 59 & 221 & 28.6 & 15.4 & 56.0 \\
\hline 2002 & 160 & 47 & 293 & 17.9 & 7.0 & 75.1 \\
2003 & 160 & 44 & 296 & 17.7 & 6.9 & 75.4 \\
2004 & 162 & 47 & 291 & 17.2 & 7.8 & 75.0 \\
2005 & 159 & 51 & 290 & 16.4 & 7.6 & 76.0 \\
2006 & 159 & 49 & 292 & 17.3 & 7.1 & 75.6 \\
2007 & 170 & 42 & 288 & 18.3 & 6.5 & 75.2 \\
2008 & 162 & 41 & 297 & 18.2 & 6.5 & 75.3 \\
\hline 2. Prom. posconv. & 162 & 46 & 292 & 17.6 & 7.0 & 75.4 \\
\hline Var.\% (2)/(1) & -26.4 & -22.0 & 32.1 & $-38-5$ & -54.5 & 34.6 \\
\hline
\end{tabular}

* Las empresas nacionales son aquellas con participación mayoritaria de capitales nacionales en la estructura accionaria de la firma (puede incluir hasta un 10 por ciento de participación de capital de origen extranjero); las asociaciones son aquellas en las que la participación accionaria del capital extranjero es mayor al 10 por ciento y menor o igual al 50 por ciento, las empresas extranjeras son aquellas con participación superior al 50 por ciento de capitales extranjeros.

Fuente: Elaboración propia en base a tabulados especiales de la Encuesta Nacional a Grandes Empresas del INDEC.

Como se mencionó, este proceso de extranjerización no estuvo disociado de la privatización de empresas públicas y de sus distintas fases. Ahora bien, las tendencias a la extranjerización se aceleraron a partir de 1995; asociadas, fundamentalmente a la dinámica que adquirió la compraventa de firmas dentro del propio capital privado, donde las transferencias de acciones de las empresas privatizadas tuvieron un papel destacado pero no excluyente. Si bien las ventas de activos fijos fueron múltiples en diversos rubros de actividad y de distinto origen/destino, los resultados reflejan que indiscutiblemente los compradores fueron en su mayoría extranjeros y los vendedores, principalmente de origen nacional. De allí que entre 1995 y 2001 se incorporaran al panel 84 empresas transnacionales y que la presencia de los inversores foráneos en el valor de producción de la élite alcanzara al 69 por ciento en el último año de vigencia del régimen de 
conversión fija (esto supone un incremento de casi 24 puntos porcentuales respecto a su participación en 1995). ${ }^{3}$

Las evidencias presentadas permiten concluir que en el crítico 2002 se incrementó fuertemente la presencia extranjera en el panel de las 500 corporaciones de mayores dimensiones del país: en apenas un año se incorporaron 23 firmas y su gravitación en el valor bruto de producción total creció alrededor de 6 puntos porcentuales, para ubicarse en el 75.1 por ciento. En los años subsecuentes, tal umbral de participación transnacional en el interior de la élite se mantuvo con escasas variaciones, tanto en cantidad de firmas como en el peso relativo a su producción, cristalizándose, en consecuencia, un grado de extranjerización sumamente elevado de la cúspide del poder económico y, por ende, de la economía argentina en su conjunto.

En esta etapa se registró una serie de "cambios de mano" a favor del capital extranjero (con una participación activa de inversores brasileños) que no casualmente involucraron a varias compañías en cuya propiedad participaban accionistas locales y que, debido a su generalizada condición de oligopolios en un mercado interno reactivado y/o por contar con bajos costos absolutos (en dólares) que favorecieron su inserción exportadora -a lo cual debe sumarse la creciente demanda mundial de commodities, garantizaban amplios márgenes de rentabilidad. Tales son los casos, entre otras firmas, de Acindar, Alpargatas, Cervecería Quilmes, Loma Negra, Moflino Hermanos, PBB Polisur, Pecom Energía, Peñaflor, Quickfood, Swift Armour y Trigaglia. Además, cabe destacar que ante el considerable nivel de extranjerización prevaleciente en muchos sectores de la actividad económica local, se verificó otro proceso relevante: la transferencia de empresas y tenencias accionarias entre capitales extranjeros. Particularmente en sectores que han devenido claves en el actual proceso económico tales como las actividades mineras (Minera Alumbrera, Minera Aguilar, Agua Rica, Cerro Vanguardia, etc.) y petroleras (Oxy-Vintage, Apache-Pioneer, Apache-PAF, etc.).

En definitiva, bajo el esquema de acumulación que se ha venido configurando tras la implosión de la convertibilidad, se han afianzado las tendencias hacia una fuerte extranjerización del "núcleo duro" del poder económico doméstico y, en consecuencia, del conjunto de la economía ar-

3 El correlato de la pronunciada extranjerización del poder económico doméstico al cabo de estos años fue la caída considerable en la participación de las restantes categorías, proceso en el que jugaron un rol decisivo la disolución de varias asociaciones y el repliegue y la reestructuración que llevaron adelante varios grupos económicos locales (Basualdo, 2006; Gaggero, 2011 y Wainer, 2010). 
gentina iniciada durante el decenio de 1990. En términos generales, se puede afirmar que la apertura económica ha favorecido principalmente a las empresas transnacionales, ya que les ha permitido incrementar su capacidad competitiva a partir de la posibilidad de localizar distintos fragmentos de su producción atendiendo los costos absolutos de cada país. En tanto que el capital nacional tuvo que ser retirado de algunas de las actividades en las que estaba inserto anteriormente $\mathrm{o}$, al menos, ser eliminado de los procesos tecnológicamente más complejos, donde su desventaja a nivel internacional es mayor. Naturalmente, el correlato de esta situación es una ostensible pérdida de "decisión nacional" en lo que atañe a la definición de ciertas temáticas relevantes para el devenir económico, político y social del país.

\section{Diferencias estructurales y diferencias de desempeño entre las grandes firmas extranjeras y locales}

Para acceder a una visión más completa del comportamiento que tienen las diferentes fracciones que integran la élite empresarial en Argentina durante la posconvertibilidad, en esta sección se analizan las principales diferencias estructurales y de performance que se manifiestan entre las firmas extranjeras, las nacionales y las asociaciones. En tal sentido, en el cuadro 2 se comprueba que durante la posconvertibilidad, las firmas controladas por inversores foráneos tuvieron una participación mayoritaria en las principales variables económicas relevadas.

\section{Cuadro 2. Distribución de las principales variables estructurales y de comportamiento de las $\mathbf{5 0 0}$ empresas más grandes de Argentina según el origen del capital de las firmas, 2003-2009}

\begin{tabular}{|l|c|c|c|c|}
\hline & $\begin{array}{l}\text { Empresas } \\
\text { nacionales }\end{array}$ & $\begin{array}{l}\text { Asocia- } \\
\text { ciones }\end{array}$ & $\begin{array}{l}\text { Empresas } \\
\text { extranjeras }\end{array}$ & Total \\
\hline Cantidad de empresas & 164 & 45 & 291 & 500 \\
Participación en la cantidad de empresas (\%) & 32.8 & 9.0 & 58.2 & 100 \\
Participación en la producción total (\%) & 18.5 & 6.9 & 74.6 & 100 \\
Participación en el valor agregado total (\%) & 16.3 & 5.8 & 77.9 & 100 \\
Participación en las utilidades totales (\%) & 12.4 & 4.7 & 82.9 & 100 \\
Participación en la ocupación total (\%) & 36.2 & 7.4 & 56.4 & 100 \\
Participación en los salarios totales abonados (\%) & 30.1 & 7.1 & 62.8 & 100 \\
Participación en la inversión bruta fija total (\%) & 16.8 & 4.2 & 79.0 & 100 \\
Participación en las exportaciones totales de bienes (\%) & 16.4 & 6.7 & 76.9 & 100
\end{tabular}




\begin{tabular}{|c|c|c|c|c|c|}
\hline$\tilde{O}$ & & $\begin{array}{l}\text { Empresas } \\
\text { nacionales }\end{array}$ & $\begin{array}{l}\text { Asocia- } \\
\text { ciones }\end{array}$ & $\begin{array}{l}\text { Empresas } \\
\text { extranjeras }\end{array}$ & Total \\
\hline$己$ & Participación en las importaciones totales de bienes (\%) & 13.6 & 4.4 & 82.0 & 100 \\
\hline 芒 & Saldo de balanza comercial (\%) & 17.7 & 7.7 & 74.7 & 100 \\
\hline$\varangle$ & $\begin{array}{l}\text { Tamaño medio por empresa según valor de producción } \\
\text { (total = } 100 \text { ) }\end{array}$ & 56.3 & 76.8 & 128.2 & 100 \\
\hline & Productividád (índice total = 100) & 45.1 & 77.8 & 138.1 & 100 \\
\hline & Salario medio (índice total = 100) & 83.3 & 96.0 & 111.2 & 100 \\
\hline & Productividad/Salario medio (total = 100) & 54.1 & 81.0 & 124.2 & 100 \\
\hline$\stackrel{0}{n}$ & Participación de los salarios en el valor agregado total (\%) & 37.2 & 24.8 & 16.2 & 20.1 \\
\hline 莺 & Superávit bruto de explotación por ocupado (total = 100) & 35.4 & 73.2 & 144.9 & 100 \\
\hline 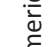 & Requerimiento de empleo (total $=100)^{*}$ & 195.7 & 107.3 & 75.6 & 100 \\
\hline 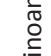 & $\begin{array}{l}\text { Tamaño medio por empresa según cant. de ocupados (total } \\
=100 \text { ) }\end{array}$ & 110.2 & 82.4 & 97.0 & 100 \\
\hline 茜 & Tasa de inversión** (\%) & 17.9 & 12.5 & 17.5 & 17.3 \\
\hline$\underline{\underline{\underline{c}}}$ & Coeficiente de exportaciones*** $(\%)$ & 25.5 & 27.6 & 29.5 & 28.7 \\
\hline$\frac{4}{d}$ & Coeficiente de importaciones**** (\%) & 6.4 & 5.4 & 9.5 & 8.7 \\
\hline & Coeficiente de apertura global ${ }^{* * * * *}(\%)$ & 31.9 & 33.1 & 39.1 & 37.3 \\
\hline & Tasa de utilidades sobre valor de producción (\%) & 8.5 & 8.7 & 14.1 & 12.7 \\
\hline & Tasa de utilidades sobre valor agregado (\%) & 24.4 & 26.3 & 34.2 & 32.1 \\
\hline & * $\quad$ Medida como el cociente entre la inversión bruta fija & el valor a & gado. & & \\
\hline & ** Medido como el cociente entre las exportaciones y l & producción & & & \\
\hline & *** Medido como el cociente entre las importaciones y & producciór & & & \\
\hline & $* * * *$ Surge de la suma entre los coeficientes de exportaci & hes y de im & ortacior & & \\
\hline & $\begin{array}{l}\text { Fuente: Elaboración propia en base a tabulados especia } \\
\text { del INDEC. }\end{array}$ & s de la En & lesta $\mathrm{N}$ & nal a Granc & mpresas \\
\hline
\end{tabular}

Así, por ejemplo, las 291 empresas extranjeras (58.2 por ciento del total) aportaron casi el 75 por ciento de la producción total, el 78 por ciento del valor agregado, alrededor del 83 por ciento de las utilidades globales, el 56.4 por ciento de la ocupación, el 62.8 por ciento de la totalidad de los salarios abonados, el 79 por ciento de la inversión bruta fija global; aproximadamente el 77 por ciento del total de exportaciones, el 82 por ciento de las importaciones agregadas y las tres cuartas partes del excedente de comercio exterior. Esos disímiles niveles de participación permiten inferir la presencia de discrepancias de consideración entre las empresas extranjeras y el resto de las compañías líderes; entre otros aspectos y en términos de los tamaños medios de las firmas: las productividades relativas, los respectivos niveles salariales, la distribución funcional del ingreso en su interior, la intensidad de la formación de capital, los márgenes de rentabilidad y las modalidades de apertura al mercado internacional.

$\mathrm{Al}$ respecto, en la etapa que ahora se analiza, el tamaño promedio de las firmas extranjeras (medido por el cociente entre el valor de la producción y la cantidad de empresas) fue un 76.8 por ciento más elevado que 
el de las asociaciones y casi un 128.2 por ciento más holgado que el de las líderes de capital nacional. La inserción del capital foráneo en diversas actividades económicas asumen un papel protagónico en ese contraste con las grandes firmas de capital nacional.

Dentro de estas actividades, las economías de escala (productivas, tecnológicas, de comercialización) se conjugan con el consiguiente liderazgo oligopólico, sumadas a la casi total ausencia de restricciones asociadas al financiamiento y/o el tamaño de mercado igualmente subsanables en el marco de una estrategia transnacional e intracorporativa. Sin embargo, las mencionadas diferencias no se restringen a una cuestión de tamaño sino que resultan aún más pronunciadas cuando se consideran las respectivas productividades de la mano de obra (valor agregado por ocupado): siempre considerando los promedios anuales 2003-2009, el rendimiento productivo promedio de los asalariados empleados en las empresas extranjeras fue casi un 76 por ciento superior al de las asociaciones y más de tres veces superior al registrado en las empresas nacionales. Este hecho pone en evidencia la debilidad relativa, en términos de competitividad, de las empresas nacionales, incluso de las grandes, frente a sus pares foráneas.

El hecho de que las brechas salariales existentes en el interior del panel de las firmas más grandes del país según el origen del capital de las mismas hayan sido mucho menos acentuadas que en el caso de las respectivas productividades del trabajo, sugiere que dentro del ámbito de las firmas líderes controladas por inversores extranjeros se manifestó una distribución del ingreso mucho más regresiva que en el resto de las grandes compañías. En este sentido, a pesar de pagar mejores salarios, los capitalistas propietarios de las empresas extranjeras se apropian de una porción mayor del excedente, o en otros términos, la tasa de explotación en estas corporaciones es mayor que entre sus pares nacionales.

Ello se visualiza en que la relación productividad/salario medio en las firmas transnacionales fue un 53.3 por ciento más elevada que en las asociaciones y cerca de un 130 por ciento superior que la registrada en el subconjunto de las líderes controladas por capitales vernáculos. Asimismo, el superávit bruto de explotación ocupado por las firmas extranjeras fue 4.1 veces más elevado que en aquellas controladas por accionistas locales y dos veces superior que el que se manifestó en las asociaciones.

De la misma manera, las corporaciones internacionales demandan una menor cantidad de mano de obra por unidad de producción que el resto del panel, situación que deriva en buena medida del hecho de que éstas son mucho más capital-intensivas que las grandes firmas locales. Esto se ve reflejado en la participación de los salarios en el valor agregado: en las 
compañías controladas por inversores foráneos fue muy inferior (16.2 por ciento) al verificado en las asociaciones ( 24.8 por ciento) y más aún, en las empresas nacionales (37.2 por ciento). La reproducción en el ámbito local, aún a diferente nivel de los estándares económico-tecnológicos prevalecientes en los países de origen de las filiales locales deriva en mayores escalas de producción así como en una composición orgánica mucho más elevada que las de sus similares nacionales. $\mathrm{Al}$ respecto, debe tenerse en cuenta que para las corporaciones foráneas prácticamente no existen rigideces (ni financieras, ni de otro tipo) que condicionen o limiten la adopción de aquellas tecnologías que les garanticen el más apropiado sendero de acumulación y reproducción ampliada del capital en el nivel doméstico, así como de la inserción de este último a escala mundial.

Por otra parte, si bien tuvieron un peso decisivo en la formación de capital realizada en conjunto por las firmas integrantes de la élite, la información que brinda el cuadro 2 indica que la tasa de inversión (sobre valor agregado) de las empresas extranjeras del panel fue levemente inferior a la de las firmas nacionales. Ello, a pesar que el nivel de apropiación del excedente por parte de las firmas extranjeras supera holgadamente al del resto de las firmas del panel. Esta diferencia entre la tasa de inversión real y la "esperada" deriva fundamentalmente de su condición de transnacionales. Buena parte del excedente adopta diversas formas, tales como la remisión al exterior de utilidades y dividendos, el pago de honorarios y regalías y la fuga de capitales por diversas vías como, por ejemplo, el manejo discrecional de los montos de exportaciones y/o importaciones en operaciones intracorporativas, la cancelación total o parcial de créditos concedidos por la propia casa matriz y / o alguna subsidiaria radicada en otro país (CENDA, 2010). En aquellos casos donde buena parte de la producción está destinada al mercado interno, esta relativa baja tasa de inversión podría estar asociada también al carácter oligopólico de varios segmentos del mismo así como al hecho de haber alcanzado, por distintos motivos, cierto grado de madurez tecno-productiva que no demanda inversiones de relativa importancia para mantener su posicionamiento competitivo.

Los datos aportados por la gráfica 2 indican contundentemente que en la posconvertibilidad, dentro del marco de una ampliación de la demanda por efecto del ciclo expansivo (local e internacional), el coeficiente global de inversión de este segmento empresario se ubicó significativamente por debajo de sus márgenes de rentabilidad. Cabe mencionar que estos marcos fueron holgadamente superiores a los internalizados en el período de la convertibilidad. En otras palabras, pese a la notable capacidad de acumulación que se abrió a partir de la devaluación de la moneda en 2002 y la 
vigencia de mercados externos en franca expansión, la contribución de las empresas transnacionales a la expansión de las capacidades productivas locales fue, en términos relativos, bastante acotada.

Gráfica 2. Participación de las utilidades y de la inversión bruta fija en el valor agregado de las empresas extranjeras que integran el panel de las $\mathbf{5 0 0}$ más grandes de Argentina, 1993-2009

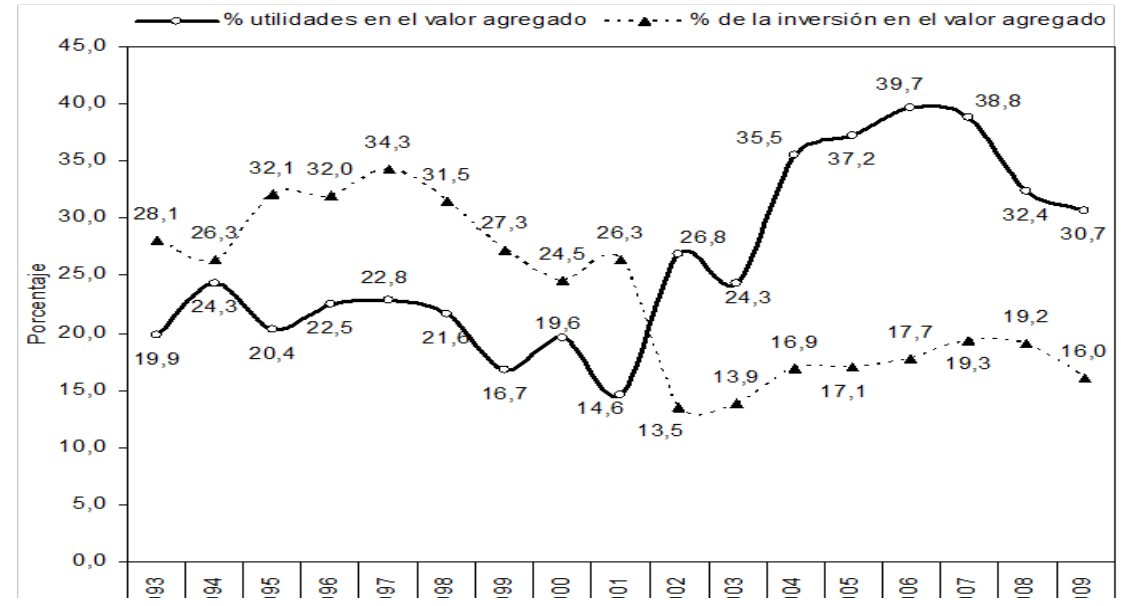

Fuente: Elaboración propia en base a tabulados especiales de la Encuesta Nacional a Grandes Empresas del INDEC.

Por supuesto que la relativa baja tasa de inversión no es privativa del capital extranjero, sino que también alcanza a las grandes empresas nacionales, las cuales suelen mantener una proporción considerable del excedente en estado líquido y, generalmente, en "moneda dura" (Azpiazu y Manzanelli, 2011). Sin lugar a dudas - al menos durante la posconvertibilidad - esta reticencia inversora no se debe a una insuficiente tasa de ganancia (Manzanelli, 2012), ni tampoco debería ser atribuida exclusivamente a una supuesta "mentalidad rentística" de la clase capitalista local. Muy probablemente, buena parte de la respuesta a este interrogante haya que buscarla en la ausencia de incentivos para invertir en sectores donde la producción local ha sido desmantelada y/o carece de ventajas comparativas estáticas donde su participación implicaría grandes inversiones para poder competir en igualdad de condiciones con el capital extranjero. 
El cual, como se vio, no tiene necesidad de realizar grandes inversiones de capital para mantener su posición privilegiada en el mercado interno.

Parecería ser que la sola caída en el costo salarial a escala internacional que propició la devaluación del peso no ha sido una condición suficiente para impulsar la recuperación o creación de nuevas ramas de producción. Especialmente en aquellos sectores capital-intensivos donde la brecha tecnológica que separa a Argentina de las naciones desarrolladas es mayor o incluso en aquellas industrias con mano de obra intensivas en las cuales predomina la producción proveniente de países periféricos con salarios mucho más bajos en términos absolutos. Parece muy difícil afirmar que con la estructura social argentina y la tradición de lucha y organización de la clase trabajadora, se puedan reducir los costos salariales al grado de hacer rentable la inversión en sectores exportadores donde predomina la producción de países como China, India, Tailandia, Vietnam, etc. Sin embargo, dada la ampliación de la brecha tecnológica durante las últimas décadas (Nochteff, 2000), tampoco parece ser suficiente la sola modificación para impulsar por sí misma la inversión para la exportación en sectores intensivos en el uso de tecnología.

Lo anteriormente dicho brinda algunos elementos de juicio en relación con los argumentos más utilizados para destacar la importancia de una presencia difundida de actores foráneos en el país. Según esta visión, tal situación podría contribuir a la modernización de la estructura productiva, ya que las empresas extranjeras tendrían una elevada propensión a invertir asociada con la introducción de bienes de capital de alta complejidad tecnológica, así como a la realización de importantes gastos en materia de investigación y desarrollo en el nivel local, con el consiguiente "efecto derrame" que ello traería aparejado.

Se suponía que la inserción de grandes empresas transnacionales beneficiaría a los países "en vías de desarrollo" a través de la transferencia de la tecnología más avanzada. Sin embargo, las evidencias disponibles sugieren que las empresas extranjeras suelen conservar en sus países de origen tanto la fabricación de equipamiento de alta tecnología, como la casi totalidad de gastos en materia de investigación y desarrollo; de allí su escaso dinamismo en lo que atañe a la generación de entramados locales virtuosos. Todo ello es particularmente importante de destacar debido a que se indica que en el plano interno, las compañías transnacionales no parecen haber sido agentes difusores de la inversión ni del cambio y/o la innovación tecnológica. Por otra parte, al ser fuertes importadoras de bienes de capital, han 
contribuido a profundizar el deterioro de la industria local de maquinaria y equipo y el desequilibrio comercial en la materia. ${ }^{4}$

En relación a lo anterior, vale incorporar un breve comentario respecto al grado de inserción en el comercio internacional de las distintas empresas que integran la cúpula. De los datos aportados por el cuadro 2, se sabe que tanto las grandes firmas de capital nacional como las que tienen más o menos participación extranjera en su propiedad accionaria, presentaron en términos globales una similar propensión exportadora (superior en el caso de las controladas por intereses foráneos). Sin embargo, cuando se analiza el peso relativo de las compras en el exterior en la producción total para cada tipo de firma, se comprueba que las empresas extranjeras realizaron, en promedio, más importaciones que el resto de las líderes: el coeficiente de importaciones de las primeras fue del 9.5 por ciento, mientras que el de las nacionales fue del 6.4 por ciento y el de las asociaciones del 5.4 por ciento.

De tal modo que las empresas extranjeras fueron las compañías que registraron el mayor coeficiente de apertura global al mercado mundial. Ello se asocia con la conjunción de diversos factores como, a modo ilustrativo, la presencia determinante de estas empresas en sectores donde las exportaciones y/o las importaciones tienen un peso relevante en la producción total: por ejemplo, la elaboración de alimentos y otros productos derivados de la explotación agropecuaria, el armado de vehículos automotores, la actividad hidrocarburífera y la minera, la fabricación de productos químicos y la producción siderúrgica. Por otro lado, ya que se trata en muchos casos de filiales de empresas transnacionales, su mayor exposición al comercio mundial puede responder al proceso de integración y/o complementación productiva en el nivel internacional de la respectiva casa matriz, así como a la distribución de áreas de mercado entre sus diferentes filiales en el exterior: tal es el caso de muchas firmas vinculadas con la industria alimenticia y a la de automóviles y sus partes.

Si bien las empresas transnacionales son las principales exportadoras, esta elevada propensión a importar sumada a la remisión de utilidades y

4 Ante la ausencia de políticas activas que induzcan lo contrario, es habitual que las empresas extranjeras que se desenvuelven en el país externalicen sus áreas de ingeniería local, reemplazándolas por la incorporación de tecnología importada y casi sin desarrollo nacional alguno. Esto disminuye los de por sí escasos vínculos de estas firmas con el entramado local de proveedores y/o subcontratistas y agudiza la problemática de la dependencia tecnológica (Ortiz y Schorr, 2009). Estas tendencias se ven potenciadas por el hecho de que en los grandes proyectos de inversión patrocinados por el gobierno nacional y/o por los provinciales suelen resultar favorecidos capitales extranjeros cuyas inversiones vienen "atadas" a la provisión de equipamiento procedente del exterior (con mayor incidencia en los rubros de más valor agregado). 
diversos mecanismos de fuga de capitales - ponen en tela de juicio el argumento de que la inversión extranjera sea un elemento que contribuya a superar la histórica restricción externa que ha caracterizado a la economía argentina. Esto se aplica, sobre todo, para la inversión extranjera en el sector industrial, donde el nivel de integración de la producción nacional suele ser muy bajo. ${ }^{5}$

Finalmente, como se vio, las empresas controladas por accionistas foráneos fueron aquellas que registraron los mayores márgenes brutos de explotación y donde los capitalistas se apropiaron de una proporción mayor del excedente generado por los trabajadores, en el contexto de una propensión inversora relativamente débil. De allí que no resulte casual que estas últimas constituyeran el segmento de las empresas líderes que en el período estudiado internalizaran las mayores tasas de beneficio (utilidades sobre valor agregado): en el período 2003-2009 el margen medio de ganancia de las líderes extranjeras fue del 34.2 por ciento, frente al 24.4 por ciento de las nacionales y el 26.3 por ciento de las asociaciones. ${ }^{6}$

\section{¿El reverso de la moneda? La internacionalización de los grupos económicos locales}

Frente a las evidencias del incremento en el nivel de extranjerización dentro del universo de las grandes empresas en Argentina, podría oponerse el argumento que sostiene que se trata de un aspecto del proceso de globalización que elimina las barreras de la libre movilidad de los capitales y somete a todos los países a las mismas reglas de juego. En este sentido, los capitales podrían fluir "libremente" allí donde la inversión resulte más ren-

5 El ejemplo paradigmático de esta propensión a importar por parte de las grandes firmas transnacionales lo constituyen las terminales automotrices radicadas en el país (Azpiazu y Schorr, 2010; Wainer, 2011).

6 En cuanto a las tasas de rentabilidad de las corporaciones extranjeras, cabe destacar que las mismas pueden estar subestimando los beneficios reales, dado que estos actores suelen desplegar distintos mecanismos de transferencia del excedente generado en el nivel doméstico. En tal sentido, y a modo ilustrativo, se destaca el establecimiento de precios de transferencia entre las filiales locales y sus casas matrices en el exterior y/o subsidiarias de la misma matriz radicadas en otro país: por ejemplo, vía la sobrefacturación de importaciones, la subfacturación de exportaciones o la cancelación de líneas crediticias (en rigor de auto préstamos). También, como en el caso particular de ciertas empresas de la cúpula que son controladas por algunos de los principales conglomerados extranjeros que actúan en el país, la posibilidad de realizar traslaciones de ingresos entre las distintas firmas que forman parte del complejo empresarial a partir de, por caso, la instrumentación de subsidios cruzados y el aprovechamiento de los beneficios derivados de la integración vertical y/u horizontal de las actividades, etc. 
table, abriendo oportunidades también a las firmas provenientes de países periféricos. En efecto, en las últimas décadas se ha observado un importante cambio en el panorama de las empresas transnacionales a nivel mundial caracterizado por un incremento de la presencia de compañías que tienen su origen en la periferia. Sin embargo, no todos los países periféricos han incrementado en igual medida su participación en la constelación de las grandes empresas a nivel mundial; a saber, el crecimiento más importante es explicado por las firmas originarias del sudeste asiático y especialmente durante los últimos años por aquellas provenientes de China. De este modo, entre 2004 y 2010 la cantidad de empresas chinas que se ubicaron entre las 500 más grandes del mundo pasó de 16 a 61, de las cuales tres figuran entre las diez primeras. ${ }^{7}$ Por su parte, las firmas procedentes del sudeste asiático pasaron de 16 en 2004 a 26 en $2010 .{ }^{8}$

En lo que respecta a América Latina, los países con mayor cantidad de empresas dentro del conjunto de las principales firmas mundiales son Brasil y México, aunque su presencia es muy inferior a la de sus pares del continente asiático. Como surge del cuadro 3, la cantidad de empresas originarias de Brasil incluidas entre las 500 con mayor facturación a nivel mundial, se incrementó de tres a siete entre 2004 y 2010, en tanto las firmas mexicanas pasaron de dos a tres. Los otros dos países latinoamericanos con presencia en el mencionado ranking en el último año considerado son Colombia y Venezuela, en ambos casos mediante compañías petroleras de propiedad estatal (Ecopetrol y PDVSA). Cabe señalar que también las empresas más grandes de Brasil y México son petroleras cuya propiedad pertenece mayoritariamente a los respectivos estados nacionales (Petrobras y Pemex), mientras que las restantes firmas son principalmente empresas de servicios, un grupo con fuerte presencia en la actividades minera y siderúrgica (Vale) y otra petrolera privada (Ultrapar). Entre todas las latinoamericanas que figuran en el mencionado ranking, sólo dos firmas brasileñas (JBS y Vale) poseen activos en la industria manufacturera, en ambos casos vinculados a la producción en sectores que cuentan con ventajas comparativas naturales (frigoríficos, minería y siderurgia).

7 En 2004 no había ninguna compañía china entre las treinta con mayor facturación del ranking elaborado por la revista Fortune Global. En 2010 Sinopec, China National Petroleum y State Grid figuraron en los puestos 5, 6 y 7 respectivamente. Las primeras dos son petroleras y la tercera es proveedora de energía eléctrica, siendo todas de propiedad estatal.

8 Entre las 500 firmas más grandes de 2010 se ubicaban 14 provenientes de Corea del Sur, 8 de Taiwán, 2 de Singapur, una de Malasia y una de Tailandia (Fortune Global). 
Cuadro 3. Número de empresas latinoamericanas entre las $\mathbf{5 0 0}$ más grandes del mundo, 2004 y 2010

\begin{tabular}{|c|c|c|}
\hline Pais & 2004 & 2010 \\
\hline Brasil & 3 & 7 \\
Colombia & 0 & 1 \\
México & 2 & 3 \\
Venezuela & 0 & 1 \\
\hline Total & 5 & 12 \\
\hline
\end{tabular}

Fuente: Elaboración propia en base a Fortune Global 500

Si bien, se asistió a un crecimiento de algunos grupos económicos de México y Brasil durante los años noventa (Garrido y Peres, 1998), el incremento en la cantidad de empresas latinoamericanas dentro del grupo de las mayores compañías del mundo se debió, en buena medida, al alza del precio del petróleo, al crecimiento del sector financiero brasileño y a la internacionalización alcanzada por algunos grupos económicos de este país, la cual fue fomentada por el Estado brasileño a través de la provisión de créditos "blandos" provistos por el Banco Nacional Do Desenvolvimento (BNDES). Aún así, el papel desempeñado por la región sigue siendo muy limitado: solo tres de las doce empresas latinoamericanas que figuraron entre las 500 con mayor facturación en 2010 integraron el panel de las 100 más grandes del mundo, mientras que cuatro se ubicaron entre la posición 100 y la 200, las cinco restantes quedaron entre las últimas 300 firmas del ranking (véase el cuadro 4).

Cuadro 4. Número de empresas latinoamericanas entre las 500 más grandes del mundo según estratos, 2010

\begin{tabular}{|c|c|c|c|c|}
\hline Pais & 1 a 100 & 100 a 200 & 200 a 500 & Total \\
\hline Brasil & 1 & 3 & 3 & 7 \\
Colombia & 0 & 0 & 1 & 1 \\
México & 1 & 1 & 1 & 3 \\
Venezuela & 1 & 0 & 0 & 1 \\
\hline Total & 3 & 4 & 5 & 12 \\
\hline
\end{tabular}

Fuente: Elaboración propia en base a Fortune Global 500

En definitiva, la presencia de grandes compañías de origen latinoamericano en el conjunto de las 500 con mayor facturación en todo el mundo sigue siendo más bien marginal y está acotada a empresas vinculadas con ventajas comparativas naturales y/o de servicios, siendo notoria la au- 
sencia de firmas manufactureras, especialmente aquellas vinculadas a la explotación de ventajas comparativas dinámicas. ${ }^{9}$

Tal como se desprende de los datos presentados, ninguna empresa argentina ha figurado en los últimos años entre las más grandes del mundo. Esto puede ser considerado como un primer indicador del menor tamaño de los grupos económicos locales en comparación con sus pares de otros países y regiones. Si bien suelen ser relativamente grandes en el medio local, a nivel global el grueso de los grupos económicos argentinos son jugadores más bien marginales. Según un relevamiento realizado por la Agencia Federal de Inversiones de Argentina, en 2011 existían veintitrés empresas argentinas con activos en exterior, aunque con un tamaño relativo muy disímil entre ellas (véase el cuadro 5).

\section{Cuadro 5. Ranking de empresas con casa central en Argentina que tienen control gerencial sobre al menos una filial en el exterior, 2011}

\begin{tabular}{|c|c|c|c|}
\hline Pos. & Empresa & Actividad principal & $\begin{array}{l}\text { Activos externos } \\
\text { (mill. USD) }\end{array}$ \\
\hline 1 & Tenaris & Derivados del acero & 10.069 \\
\hline 2 & Ternium & Derivados del acero & 7.623 \\
\hline 3 & Grupo Insud & Farmacéutica & 986 \\
\hline 4 & Arcor & Productos alimenticios & 559 \\
\hline 5 & Los Grobo & Producción agropecuaria & 414 \\
\hline 6 & IMPSA & Maquinaria y equipo & 369 \\
\hline 7 & Bagó & Farmacéutica & 211 \\
\hline 8 & Molinos Río de la Plata & Productos alimenticios & 168 \\
\hline 9 & Cresud & Producción agropecuaria & 141 \\
\hline 10 & Corporación América & Aeropuertos e infraestructura & 100 \\
\hline 11 & IECSA & Ingeniería civil & 63 \\
\hline 12 & TECNA & Construcción & 56 \\
\hline 13 & Grupo Assa & Servicios de TI & 34 \\
\hline 14 & S.A. San Miguel & Productos alimenticios & 29 \\
\hline 15 & CLISA & Recolección y tratamiento de residuos & 14 \\
\hline
\end{tabular}

9 De acuerdo al trabajo de Garrido y Peres (1998), las grandes empresas industriales de origen local en Brasil y México que lograron consolidarse en los años noventa ante el avance general del capital extranjero estaban concentradas en unos pocos sectores "tradicionales" o en la producción de bienes homogéneos de consumo masivo para el mercado interno, en todo los casos con escaso contenido tecnológico. 


\begin{tabular}{|c|c|c|c|c|}
\hline \multirow{4}{*}{ 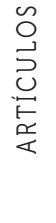 } & Pos. & Empresa & Empresa & Empresa \\
\hline & 16 & Globant & Servicios de TI & 12 \\
\hline & 17 & Petroquímica Río Tercero & Productos químicos & 11 \\
\hline & 18 & Grupo Plastar & Plásticos y caucho & 5 \\
\hline \multirow{6}{*}{ 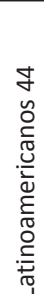 } & 19 & Sancor & Productos alimenticios & 4 \\
\hline & 20 & Bolland & Servicios para la industria petrolera & 3 \\
\hline & 21 & Havanna & Servicios de alimentos y bebidas & 2 \\
\hline & 22 & BGH & Computación y electrónica & 2 \\
\hline & 23 & Bio Sidus & ¿nvestigación y desarrollo & 1 \\
\hline & & Total & & 20.875 \\
\hline
\end{tabular}

Fuente: Nofal-VCC survey of Argentine multinationals, 2011.

Efectivamente, a pesar de que son en total veintitrés las firmas argentinas con activos en el extranjero, existe una dispersión muy importante entre ellas que obliga a diferenciarlas en al menos tres grandes grupos. Primero, se encuentran dos empresas con un importante acervo de activos en el exterior, Tenaris y Ternium, ambas pertenecientes al grupo Techint, principal holding privado de origen local. En conjunto, ambas firmas presentan activos externos por 17692 millones de dólares, es decir, casi el 85 por ciento del total de los activos externos de las compañías argentinas con presencia en el extranjero. En el segundo grupo se ubican 8 empresas que tienen una presencia en el exterior más limitada, conjunto que está compuesto por compañías farmacéuticas, agropecuarias y agroindustriales. El tercer grupo está conformado por el resto de las empresas (13) que poseen activos en el extranjero; está caracterizado por presentar exiguos montos de inversión en el exterior, fundamentalmente ligados a actividades de comercialización (véase el cuadro 6).

\section{Cuadro 6. Distribución de los activos en el extranjero según grupos de empresas argentinas, 2011}

\begin{tabular}{|l|r|r|}
\hline \multirow{2}{*}{ Grupos de empresas } & \multicolumn{2}{|c|}{ Activos en el extranjero } \\
\cline { 2 - 3 } & mill. USD & $\%$ \\
\hline $\begin{array}{l}\text { Grupo 1 } \\
\text { (Tenaris, Ternium) }\end{array}$ & 17,692 & 85 \\
\hline $\begin{array}{l}\text { Grupo 2 } \\
\text { (Insud, Arcor, Los Grobo, IMPSA, Bagó, Molinos Río de la Plata, Cresud, Corporación } \\
\text { América) }\end{array}$ & 2,948 & 14 \\
\hline $\begin{array}{l}\text { Grupo 3 } \\
\text { (IECSA, TECNA, Grupo Assa, S.A. San Miguel, CLISA, Globant, Petroquímica Río } \\
\text { Tercero, Grupo Plastar, Sancor, Bolland, Havanna, BGH, Bio Sidus) }\end{array}$ & 236 \\
\hline Total & 20,875 & 100 \\
\hline
\end{tabular}

Fuente: Elaboración propia en base a información de Nofal-VCC survey of Argentine multinationals, 2011. 
En sólo siete de las veintitrés empresas consideradas, la facturación en el extranjero superó el 50 por ciento del total en el año 2011. Es decir, las ventas de sus filiales en el exterior fueron mayores que las realizadas por las filiales en Argentina. De todas ellas, sólo tres compañías exhiben ventas por un monto mayor a los mil millones de dólares: Tenaris, Ternium y Molinos Río de la Plata (véase el cuadro 7). Este último caso es bastante distinto a los de las firmas del grupo Techint, ya que mientras que en los primeros dos casos también es ampliamente mayoritario el peso de los activos extranjeros sobre el total y la cantidad de empleados en el exterior supera a los que tienen en territorio argentino, en el caso de Molinos Río de la Plata los activos en el extranjero sólo representan el 17.2 por ciento de los activos totales del grupo y los empleados en las filiales en el exterior apenas alcanzan al 2.7 por ciento del total de trabajadores de la compañía (Nofal, 2011). Esto se debe a que la mayor parte de las filiales contabilizadas como extranjeras realizan mayormente tareas de comercialización y no de producción.

Como se puede apreciar en el cuadro 7 , en otras cuatro firmas las ventas en el exterior representan entre el 20 y el 50 por ciento del total, en tanto las doce restantes obtienen menos del 20 por ciento de sus ingresos totales de actividades en el extranjero. Esta baja incidencia de los ingresos generados en el exterior sobre el total, demuestra que la mayor parte de las multinacionales argentinas continúan dependiendo principalmente de sus actividades en el país.

\section{Cuadro 7. Relación entre ventas externas y ventas totales de empresas} transnacionales de la Argentina, 2011

\begin{tabular}{|l|r|r|r|}
\hline Empresa & \multicolumn{1}{|c|}{$\begin{array}{r}\text { Vtas. externas } \\
\text { (I) }\end{array}$} & $\begin{array}{c}\text { Vtas. totales } \\
\text { (II) }\end{array}$ & $\begin{array}{c}\text { Incidencia (\%) } \\
\text { (V/WI) }\end{array}$ \\
\hline Grupo Assa & 41 & 45 & 91.1 \\
Grupo Insud & 663 & 800 & 82.9 \\
Molinos Río de la Plata & 1.772 & 2.154 & 82.3 \\
Tenaris & 5.864 & 8.149 & 72.0 \\
TECNA & 101 & 146 & 69.2 \\
Ternium & 3.351 & 4.959 & 67.6 \\
Los Grobo & 435 & 692 & 62.9 \\
Bagó & 297 & 749 & 39.7 \\
Arcor & 813 & 2.155 & 37.7 \\
BGH & 102 & 328 & 31.1 \\
IMPSA & 173 & 623 & 27.8
\end{tabular}




\begin{tabular}{|c|c|c|c|c|}
\hline \multirow{4}{*}{ 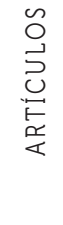 } & Empresa & $\begin{array}{l}\text { Vtas. externas } \\
\text { (I) }\end{array}$ & $\begin{array}{l}\text { Vtas. totales } \\
\text { (II) }\end{array}$ & $\begin{array}{c}\text { Incidencia (\%) } \\
\text { (I/III) }\end{array}$ \\
\hline & Globant & 6 & 39 & 15.4 \\
\hline & IECSA & 59 & 506 & 11.7 \\
\hline & Corporación América & 47 & 405 & 11.6 \\
\hline \multirow{9}{*}{ 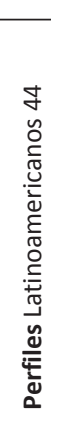 } & Bolland & 11 & 102 & 10.8 \\
\hline & S.A. San Miguel A.G.I.C.I.yF. & 18 & 179 & 10.1 \\
\hline & Cresud & 60 & 636 & 9.4 \\
\hline & Petroquímica Río Tercero & 10 & 118 & 8.5 \\
\hline & Grupo Plastar & 6 & 90 & 6.7 \\
\hline & Havanna & 2 & 49 & 4.1 \\
\hline & Sancor & 16 & 735 & 2.2 \\
\hline & CLISA & 4 & 550 & 0.7 \\
\hline & Bio Sidus & 0 & 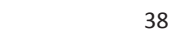 & thes \\
\hline
\end{tabular}

Otro indicador del limitado nivel de transnacionalización de la mayor parte de los grupos económicos locales es su fuerte concentración en la región latinoamericana, y más específicamente, en Sudamérica. De las 278 filiales que poseen estos grupos fuera de Argentina, 176, es decir, el 63 por ciento, corresponden a Latinoamérica. El resto se distribuye entre Europa (15 por ciento), Norteamérica (10 por ciento), el este de Asia y el pacífico (7 por ciento) y Medio Oriente y el norte de África (3 por ciento) (Nofal, 2011). Dentro de Latinoamérica, se destaca especialmente la presencia de grupos económicos argentinos en los países limítrofes (Brasil, Uruguay, Paraguay, Chile y Bolivia). En este sentido, se puede afirmar que la mayor parte de las grandes transnacionales argentinas tienen un carácter mucho más regional que mundial, de tal forma que sólo tres firmas (Tenaris, Insud e IMPSA) tienen más de la mitad de sus filiales radicadas fuera de la región. De los datos hasta aquí presentados surgen algunas conclusiones significativas:

- Las grandes empresas argentinas tienen, por lo general, un tamaño muy inferior a las de los países centrales.

- En los últimos años ha quedado en evidencia que las empresas argentinas también se han mantenido muy rezagadas frente a las de buena parte de la periferia recientemente industrializada e incluso frente a sus pares, Brasil y México.

- De las veintitrés empresas de origen local que poseen activos en el extranjero, menos de la mitad pueden ser consideradas 
como "transnacionales", en tanto sólo dos empresas ambas pertenecientes al mismo grupo económico tienen un lugar preponderante en el escenario internacional.

- Ninguna de las empresas que forman el listado de multinacionales argentinas son de propiedad estatal. ${ }^{10}$

- Con la excepción de un puñado de empresas, el grueso de las "transargentinas" tiene un alcance prácticamente limitado a la región latinoamericana y, sobre todo, a los países limítrofes.

- La suerte de la mayor parte de las compañías argentinas con activos en el exterior sigue estando atada principalmente al desempeño de sus actividades en el país.

- El perfil general de las firmas denota actividades con poco valor agregado, productos con bajo contenido tecnológico y, sobre todo, poco dinámicas en investigación y desarrollo. ${ }^{11}$

De este modo, se puede concluir que, en realidad, un sólo grupo económico argentino posee verdadera relevancia a nivel mundial (Techint). En tanto, hay un conjunto de empresas con algún tipo de actividad más o menos importante en determinados países principalmente dentro de Latinoamérica y otro conjunto de empresas que, a pesar de poseer activos en el extranjero, difícilmente puedan ser consideradas como grandes firmas multinacionales.

\section{Conclusiones}

La tendencia a la extranjerización del gran capital en la economía argentina se ha convertido en un dato estructural y no se debe a factores meramente coyunturales. El rol central que juegan las grandes empresas extranjeras ha reforzado en ciertos aspectos la dependencia económica. Dicho proceso de extranjerización se debió principalmente a la incapacidad del grueso de las grandes empresas argentinas para competir en igualdad de condiciones

10 A partir de la nacionalización de los fondos de pensión y jubilación que estaban en manos de entidades financieras, (AFJP) el Estado adquirió paquetes accionarios en algunas empresas privadas (como en el caso de Techint) y en ningún caso obtuvo el control de la firma ya que se trató de paquetes minoritarios.

11 La única empresa multinacional argentina que puede considerarse como productora de bienes de alto contenido tecnológico es IMPSA (del grupo Pescarmona). Por otra parte, las compañías farmacéuticas son las que muestran una mayor proporción en inversión en investigación y desarrollo aunque de todos modos siguen siendo montos bajos comparados con los de los países centrales (CEP, 2007). 
con sus pares transnacionales tras los intensos procesos de apertura económica y de profunda desregulación de la economía impulsados durante la década de 1990. Dichas reformas estructurales no se han revertido en la posconvertibilidad, a pesar de la modificación del tipo de cambio. Esto último queda nuevamente en evidencia al constatar que prácticamente no hay empresas argentinas verdaderamente transnacionales más allá de las que pertenecen al Grupo Techint y, en menor medida, la alimenticia Arcor. ${ }^{12}$ En el mejor de los casos, se cuenta otro puñado de empresas con presencia en algunos pocos países, principalmente en Latinoamérica. La transnacionalización de los grupos económicos argentinos no sólo es muy inferior a los de sus pares del sudeste asiático y China sino incluso frente a los de Brasil y México, por ejemplo.

Aun así, más allá de la consolidación en los últimos años de algunas empresas transnacionales originarias de América Latina, el rasgo predominante dentro de las burguesías latinoamericanas sigue siendo su debilidad relativa y, sobre todo, su escasa o limitada base industrial. En efecto, si se compara el rol desempeñado por las empresas transnacionales de América Latina frente a sus ascendentes pares del sudeste asiático y China, se observa que la diferencia no sólo es aplicable a sus dimensiones sino también en términos de desarrollo tecnológico. En este punto conviene diferenciar claramente dentro de la periferia aquellos países de industrialización reciente considerados "exitosos" de los países que, por el contrario, han visto involucionar su estructura industrial. Entre los primeros se encuentran Corea, Taiwán, China y, en ciertos aspectos, India. Mientras que entre los segundos, se encuentra la mayor parte de los países latinoamericanos y, de especial forma por el relativo e importante grado de integración que habían alcanzado en su estructura industrial tras la segunda guerra mundial, Argentina y Brasil. Mientras que entre los primeros, buena parte de las empresas industriales líderes son nacionales, predomina la adaptación y el

12 Si bien en 2011 el Grupo Insud superó en cantidad de activos en el extranjero a Arcor (que quedó en el tercer lugar), existen variados motivos para considerar que esta última es "más transnacional" que la primera. Tal como se desprende de los datos presentados previamente, Arcor no sólo es una empresa más grande que Insud, sino que factura más en el exterior que esta. Por otro lado, las exportaciones de Arcor superan largamente las exhibidas por Insud. Además debe considerarse que este último aglomera a un conjunto de empresas que no necesariamente tienen relación entre sí, adquiriendo más la estructura de holding que de una empresa verdaderamente integrada. En este sentido, todas las empresas bajo control de Arcor están relacionadas con su actividad principal: la producción de alimentos. De esta manera Arcor se convirtió en el primer productor mundial de caramelos y el mayor exportador de golosinas de Argentina, Brasil y Chile. Este grupo vende productos en alrededor de 120 países a partir de la producción realizada en 40 unidades productivas instaladas en Argentina (29), Brasil (5), Chile (4), Perú (1) y México (1). 
desarrollo interno de tecnología y la relación con las empresas extranjeras es de competencia, entre los segundos las principales firmas manufactureras son extranjeras. En éstas predomina la adquisición de paquetes tecnológicos cerrados y la relación de las grandes compañías nacionales con las empresas transnacionales es mayormente de integración (Amsden, 2001).

Ciertamente en Argentina no han existido políticas que fomenten la internacionalización de los grupos locales. De cualquier manera, para explicar la inexistencia de "campeones nacionales" no parece suficiente argumentar la mera ausencia de "voluntad política". La internacionalización de las relaciones de producción capitalistas no tiene un impacto "neutral" en los distintos espacios nacionales sino que está mediatizado por el desarrollo desigual de las distintas economías. A su vez, tampoco es igual la forma en que los distintos países periféricos procesan los cambios y se insertan en las redes globales de comercio y producción. En este sentido, la forma de inserción de una economía en el mercado mundial está sobredeterminada por las relaciones de clase dentro de cada espacio nacional y, fundamentalmente, por la composición del bloque dominante.

Si bien en algunos casos las burguesías latinoamericanas emergentes del proceso de industrialización por sustitución de importaciones conservan la producción de productos primarios y el procesamiento de los mismos además de participar en la producción de bienes de consumo masivo para los sectores de menores ingresos y de incursionar solas o asociadas en la producción de algunos bienes intermedios considerados estratégicos por el Estado-, en general realizan actividades complementarias y no competitivas con las filiales extranjeras. De allí que, aún cuando efectivamente algún grupo económico local logra una internacionalización medianamente exitosa, mantienen por lo general un perfil vinculado con el aprovechamiento de las ventajas comparativas naturales y, por lo tanto, se relevan mayormente incapaces de diversificar su base productiva, manteniéndose subordinados a la lógica del capital transnacional.

Difícilmente se encuentra entre las prioridades de las empresas trasnacionales el modificar sustancialmente el rol de la economía argentina en el mercado mundial, mucho menos cuando la misma no ofrece ventajas comparativas más allá de su abundante dotación de recursos naturales. Tampoco parece existir una burguesía nacional dispuesta a llevar un proyecto de país distinto al que surge "naturalmente" de la nueva y, paradójicamente, bastante tradicional a la vez división del trabajo internacional. En este contexto, la posibilidad de romper con los lazos de dependencia que aún mantiene la región latinoamericana parece asociada a la emergen- 
cia de un nuevo sujeto social cuyo interés necesariamente contradiga las tendencias "naturales" del capital a nivel mundial.

\section{Bibliografía}

Abeles, Martín, 1999, “El proceso de privatizaciones en la Argentina de los noventa. ¿Reforma estructural o consolidación hegemónica?”, Época. Revista argentina de economía política, núm. 1, Buenos Aires, pp. 95-114.

Amsden, Alice, 2001, The Rise of "The Rest": Challenges to the West from Late-industrializing Economies. New York, Oxford University Press.

Arceo, Enrique, 2005, “El impacto de la globalización en la periferia y las nuevas y viejas formas de dependencia en América Latina", Cuadernos del CENDES, núm. 60, Caracas, pp. 27-63.

Arceo, Enrique, 2009, “América Latina. Los límites de un crecimiento exportador sin cambio estructural", en Enrique Arceo, y Eduardo Basualdo (comps.), Los condicionantes de la crisis en América Latina. Inserción internacional y modalidades de acumulación, Buenos Aires, CLACSO, pp. 63-118.

Azpiazu, D. y M. Schorr, 2010, Hecho en Argentina. Industria y economía, 19762007, Buenos Aires, Siglo Veintiuno Editores.

Azpiazu, D. y P. Manzanelli, 2011, “Reinversión de utilidades y formación de capital en un grupo selecto de grandes firmas (1998-2009)", Realidad Económica, núm. 257, Buenos Aires, pp. 56-81.

Azpiazu, D., P. Manzanelli y M. Schorr, 2011, Concentración y extranjerización. La Argentina en la posconvertibilidad, Buenos Aires, Capital Intelectual: Buenos Aires.

Basualdo, Eduardo, 2006, Estudios de Economía Argentina, Buenos Aires, Siglo XXI Editores.

CENDA, 2010, “Comportamiento del sector externo argentino durante la posconvertibilidad. Una mirada a través del Balance de Pagos”, Notas de la Economía Argentina, núm. 7, Buenos Aires.

CEP, 2007, "Contenido tecnológico de las exportaciones argentinas 19962007. Tendencias de upgrading intersectorial", Ministerio de Industria, 
disponible en http://www.cep.gov.ar/descargas_new/contenido_tecnolgico_exportaciones_19962007.pdf

CONADE, 1973, "El desarrollo industrial en la Argentina: sustitución de importaciones, concentración económica y capital extranjero (19501970)", Buenos Aires, mimeo.

Gaggero, Alejandro, 2011, “Los múltiples caminos de la retirada. Estrategias y desempeños de los grupos económicos nacionales en Argentina, entre la hiperinflación y el derrumbe de la convertibilidad (1989-2002)", Tesis de Doctorado, Facultad de Ciencias Sociales, Universidad de Buenos Aires.

Garrido, C. y W. Peres, 1998, “Grandes empresas y grupos industriales latinoamericanos", Revista CEPAL, núm. 66, pp. 127-147.

Manzanelli, Pablo, 2012, "La tasa de ganancia durante la posconvertibilidad. Un balance preliminar", Apuntes para el Cambio, núm. 3, Buenos Aires, pp. 5-17.

Mauro Marini, Ruy, 2007, América Latina, dependencia y globalización, Buenos Aires, CLACSO-Prometeo Libros.

Nofal, Beatriz, 2011, "Argentine multinationals remain industrially diversified and regionally focused", Vale Columbia Center On Sustainable International Investment, disponible en http://www.vcc.columbia. edu/files/vale/documents/EMGP-Argentina-Report-2011-Final-30 Nov_11.pdf

Ortiz, R. y M. Schorr, 2009, “Dependencia tecnológica e industria trunca en la Argentina de la posconvertibilidad", Industrializar Argentina, núm. 10, Buenos Aries, pp. 12-17.

Wainer, Andrés, 2011, "Más allá del consenso monetario: Grandes empresas", Problemas del Desarrollo, vol. 42, núm. 164, México, IIEC-UNAM, pp. 99-126.

Wainer, Andrés, 2010, “Burguesías exportadoras: ¿un camino para el desarrollo de América Latina? El caso de la Argentina reciente", Cuadernos del CENDES, vol. 27, núm. 75, Caracas, pp. 95-117.

Recibido el 21 de agosto de 2012 Aceptado el 27 de febrero de 2014 